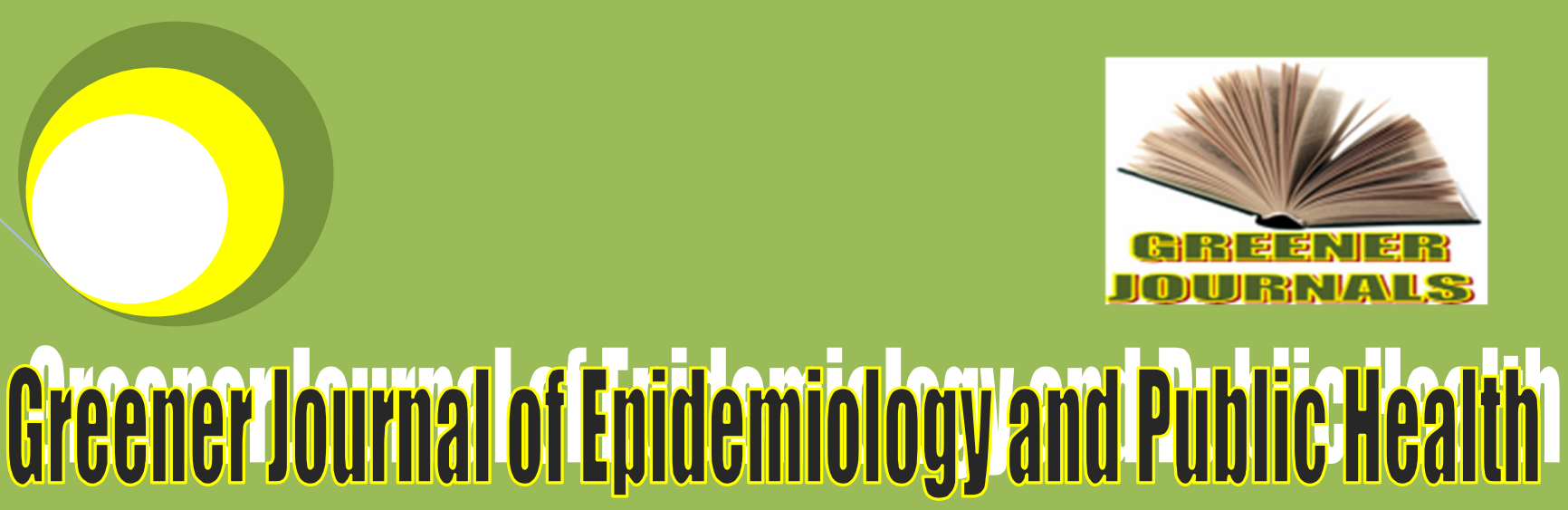

ISSN: 2354-2381

Submitted: 22/08/2016

Accepted: 24/10/2016

Published: 31/10/2016

DOI: http://doi.org/10.15580/GJEPH.2016.2.082216132

\title{
Male Involvement in
}

Maternal Health Care

in Jimeta Metropolis,

Adamawa State,

Nigeria

By

Mfuh Anita Yafeh

Lukong Christopher Suiye Olokoba Opeyemi Eunice Zubema Hyadita Janet 


\title{
Male Involvement in Maternal Health Care in Jimeta Metropolis, Adamawa State, Nigeria
}

\author{
Mfuh Anita Yafeh ${ }^{1^{*}}$, Lukong Christopher Suiye ${ }^{2}$, \\ Olokoba Opeyemi Eunice ${ }^{3}$, Zubema Hyadita Janet ${ }^{4}$
}

\author{
${ }^{1} \mathrm{PhD}$, FWACN, Lecturer, Department of Nursing Sciences, Faculty of Medicine, Ahmadu Bello University, Zaria, \\ Nigeria. \\ 2FWACS, FACS, Department of Surgery, Usmanu Danfodio University Teaching Hospital, Sokoto, Nigeria \\ ${ }^{3}$ BNSc Department of Nursing Sciences, Faculty of Medicine, Ahmadu Bello University, Zaria, Nigeria. \\ ${ }^{4}$ BNSc Department of Nursing Sciences, Faculty of Medicine, Ahmadu Bello University, Zaria, Nigeria.
}

*Corresponding Author’s Email: yaanita123456z@ gmail. com; Phone: +2348032829978

\begin{abstract}
This study was aimed to examine men's knowledge and perception in Maternal Health care at Jimeta Metropolis of Adamawa State, Nigeria. Male involvement in maternal health care, factors affecting male involvement in maternal health care and perceived effects of male involvement in maternal health care were explored. This was a cross sectional descriptive study. A multistage cluster sampling technique was adopted for the study. A total of 370 respondents were included with a response rate of $92.7 \%$. Included participants were men of reproductive age residing in Jimeta Metropolis. Data was collected using a structured questionnaire and analyzed using Statistical Package for Social Sciences Version 21. Result of the study showed poor knowledge about maternal health care as majority $(\mathbf{7 0 . 8 \%})$ of the respondents were not aware of the number of times a woman should attend antenatal clinic, $60.5 \%$ did not know the services offered for women and $58.9 \%$ did not know the danger signs of pregnancy. Result on male involvement showed that, more than half $(56.8 \%)$ of the men gave consent to their wives to attend antenatal clinic, $76.5 \%$ gave consent for their wives to go for delivery in a health facility, $43.4 \%$ allowed their wives to attend post-natal clinic and $\mathbf{5 2 . 1 \%}$ provided fund for delivery for their wives. Religious/cultural factors $(\mathbf{2 8 . 2} \%)$ and ignorance $(25.9 \%)$ were found to be the most likely reasons for men not participating in maternal health care. Although their overall knowledge of the type of maternal health services was above average (58\%), no association was found between knowledge and male involvement in maternal health care $(P=0.062)$. ). A significant difference was observed between educational attainment, ethnicity with male involvement in maternal health care $(x 2=26.43, p$ value $<0.0001$ and ethnicity $X^{2}=47.24, p$ value $<0.0001$ respectively. Health workers attitude towards male involvement in maternal health care was not statistically significant with $x^{2}=1,477$, $p$-value $=0.224$. There was an association between couples joint decision making and male involvement in maternal health care, $x^{2}=63.3, p$ value $=0.0001$. Joint decision made by couples was discovered to be a positive factor in male involvement in maternal healthcare. It was therefore recommended that, male involvement should be encouraged at all levels of healthcare. Invitation letters should be given to women attending maternal health service centres to invite their partners for more enlightenment and effective communication between couples, thereby encouraging joint decision making.
\end{abstract}

Key words: Male, Involvement, Maternal, Health, Care, Jimeta.

\section{INTRODUCTION}

Maternal health refers to the broad apparent and currently accepted means of providing promotive, preventive, curative and rehabilitative health care for mothers (Lucas and Gilles, 2003). WHO (2006) defines maternal health is the health of a woman during pregnancy, childbirth and post-partum period. These health services include: preconception care, antenatal care (ANC), prevention of mother-to-child transmission (PMTCT) of HIV, safe delivery (intrapartum care), postnatal care (PNC), and emergency obstetric care/management of obstetric complications. However, for the purposes of this study, maternal health care services here refer to antenatal care, delivery and postnatal care. Maternal mortality is one of the major challenges to health systems in the world and sub Saharan Africa in particular (Hogan, Foreman, Naghavi et al, 2010). Maternal mortality is defined as the death of a woman while pregnant or within 42 days of termination of pregnancy, regardless of the site or duration of pregnancy, from any cause related to or aggravated by the pregnancy or its management. Maternal mortality is outrageously high globally; over 289,000 women die from pregnancy and child birth related complications around the world every year, about 800 women die every day and $99 \%$ of the deaths occur in the developing countries (WHO, 2013). According to WHO (2015), the global lifetime risk of maternal mortality is approximately 1 in 180 for 2015. The World Bank (2014) stated that, all the deaths are preventable. Maternal mortality and morbidity is 
on the increase in some African countries including Nigeria despite major steps and means taken to avert it (WHO, 2006). Analysis of global, regional and sub-regional estimates of the causes of maternal death during 2003-2009 updating the previous WHO systemic reviews from 23 eligible studies published 2003 -2012 including 417 datasets from 115 countries comprising 60799 deaths revealed that $73 \%$ of all maternal deaths were due to direct obstetric causes and death due to indirect causes account for $27.5 \%$. Hemorrhage accounted for $27.1 \%$, hypertensive disorders $14.0 \%$ and sepsis $10.7 \%$ of maternal deaths. The rest of the death are due to abortions (7.9\%), embolism (3.2\%), and all other direct causes of death (9.6\%) (WHO, 2014).

Globally, an estimated 289000 women died during pregnancy and childbirth in 2013, a decline of $45 \%$ from levels in 1990. Most of them died because they had no access to skilled routine and emergency care. Since 1990, some countries in Asia and Northern Africa have more than halved maternal mortality. There has also been progress in sub-Saharan Africa. But, unlike in the developed world where a woman's life time risk of dying during pregnancy and childbirth is 1 in 3700 , the risk of maternal death is very high at 1 in 38 . Increasing numbers of women are now seeking care during childbirth in health facilities and therefore it is important to ensure that quality of care provided is optimal (WHO, 2015).

Despite challenges of measuring maternal mortality, the need for monitoring it is a priority for many countries including Nigeria. Estimates of maternal mortality are indispensable for planning and monitoring the outcomes or impact of interventions. Recently, Nigeria expressed reservations about accuracy and methods used to obtain figures quoted and the bases for such estimates (Nigeria Federal Ministry of Health (2011). The UN Secretary-General's Global Strategy for Women's and Children's Health aim to prevent 33 million unwanted pregnancies between 2011 and 2015 and to save the lives of women who are at risk of dying of complications during pregnancy and childbirth, including unsafe abortion (WHO, 2015).

In order to encourage the international community to address this challenge, maternal mortality reduction was included as one of the Millennium Development Goals, MDG 5. The target of MDG 5 was to reduce maternal mortality ratio (MMR) by 75\%, from 1990 to 2015 (United Nations General Assembly, United Nations Millennium Declaration, 2000). The drive to make progress on MDG 5 which was on improve maternal health has seen improvements in maternal health. With a baseline figure of 1000 deaths per 100,000 live births in 1990, the Maternal Mortality Rate (MMR) consistently decreased over the years by $20.0 \%$ between 1990 and 2004 and by $36.0 \%$ between 2004 and 2008 to 545 in 2008. The downward trend continued to 350 deaths per 100,000 live births in 2012 and subsequently to its end-point status of 243 per 100,000 live births in 2014 ( Nigeria Millenium Development Goal End Report, 2015). Many policy drivers made the progress possible; one being the Midwives Service Scheme while the other was the collaborative efforts made between donors and the Federal Ministry of Health and its parastatals. In the case of antenatal coverage, significant progress was also recorded. Antenatal coverage of at least one visit recorded an end-point status of $68.9 \%$ in 2014 , and for at least four visits, the endpoint status was $60.6 \%$ in 2014 . However, Nigeria's current status, estimated at 350 maternal deaths per 100,000 live births, is still $40.0 \%$ short of the 2015 target of 250 maternal deaths per 100,000 live births (Nigeria 2013 Millenium Development Goal Report). The successes imply the need for a scale-up of the policy interventions. This serves as a transitional document linking Nigeria's MDGs era and the post-MDGs development framework now officially known as the Sustainable Development Goals (SDGs)( Nigeria Millenium Development Goal End Report, 2015). ).

A report by Ezeanochie, Olagbuji, Agholor and Okonofua (2010) showed an average maternal mortality ratio in Northern Nigeria to be 2420 (range:1060 - 4477) per 100,000 live births, while similar data in the Southern parts of the country were considerably lower - between 454 and $772 / 100,000$ live births. They stated that there is an increasing evidence that this difference in maternal mortality between the Northern and Southern parts of the country may be due to disparity in the accessibility and utilisation of health services, especially differences in the availability of skilled birth attendants between the regions. The data also showed remarkable regional differences in this indicator within the country. While $81.8 \%$ and $76.5 \%$ of births were attended by Skilled Birth Attendants in the Southeast and Southwest regions respectively, only $15.5 \%$ in the North-east and $9.8 \%$ in the Northwest regions of the country were attended by skilled providers (National Population Commission (NPC) (Nigeria) and ICF Macro, 2009). There have been further reports of low utilisation of Skilled Birth Attendants in Northern Nigeria and the challenges this poses for the progress in achieving MDG 5 in the region (Ezeanochie, Olagbuji, Agholor and Okonofua (2010). These include, a population-based random survey of 6,809 women in Northern Nigeria which showed a high rate of utilisation of unskilled birth attendants (Doctor and Dahiru, 2010). The data showed that unskilled birth attendants were more likely to deliver low quality maternity care when compared to skilled health workers. This is in line with the findings from the $2008 \mathrm{NDHS}$, which suggested that if the trend continues attaining the MDG 5 in Northern Nigeria would be a nightmare (Ezeanochie, Olagbuji, Agholor and Okonofua (2010). Another report by Dalyop et al (2010) also demonstrates similar results of high use of unskilled birth attendants in North Central Nigeria, and its negative effects on maternal health. Poor referral practices by traditional birth attendants in North-central Nigeria, and its negative consequences for maternal health indicators has also been reported (Abodunrin, Akande, Musa , Aderibigbe, 2010). While the availability of health personnels and equipments are essential for the attainment of the sustainable development goals for the reduction of maternal mortality in the Northern part of Nigeria, other factors such as male involvement among other factors in maternal health care is also of paramount importance. 
Male involvement in maternal healthcare has been described as a process of social and behavioural change that is needed for men to play more responsible roles in maternal health care with the purpose of ensuring the wellbeing of women and children (ICPD, 1994). Male involvement in maternal health implies that a man should discuss maternal health issues with his spouse and they should make a joint decision on seeking good maternal health care services. The inability to involve men in maternal health promotion, prevention and care programs by policy makers, program planers and implementers of maternal health services has had a serious impact on the health of women and the success of programs (White et al, 2003). In most African countries, maternal health issues particularly family planning, pregnancy and childbirth have been long regarded as a woman's affair only.

Lack of male involvement has been attributed to be one of the barriers for accessing and utilization of maternal health services by women. The importance of men to women's reproductive health has been emphasised (International Conference on Population and Development (ICPD), 1994). Men's behaviour can significantly affect the outcome of mother's health and their babies (Mullick et al, 2005). Maternal deaths in Nigeria make up to one third of the world's burden of maternal deaths (WHO, 2012).

In Nigeria as in most other African countries, the social system of Patriarchy is practiced. Males are the primary figures and hold authority over women and children thus implicating female subordination. Men are more educated and usually have one means or the other of making a living as compared to the females who have to depend on them for virtually everything. The United Nations expert group on women and finance stated that 70 percent of the global populations who survive on less than one dollar a day are women. Furthermore, women are more likely to be uneducated which will negatively influence their health seeking behaviour (Were, 2009).

According to Becker and Robinson (1998) and Bustamante-Forest and Giarratano (2004), changing and improving the way men are involved in reproductive health problems can have a positive impact on women's, men's and children's health. Evidence also shows that men can prevent unintended pregnancies, reduce unmet need for family planning (FP), foster safe motherhood and practice responsible fatherhood (2004). In the USA, partner involvement in pregnancy has increased antenatal care (Martin, McNamara, Milot, Halle, Hair, 2007). In India, a maternity care model that encouraged husband's participation in their wives' antenatal and postnatal care found positive changes in knowledge, gender roles and decision-making (Varkey, Mishra, Das, Ottolenghi, Huntington, Adamchak, Khan, Homan, 2004). In addition, demographic and health surveys in five Latin American countries (Bolivia, Peru, Colombia, Haiti and Nicaragua) indicated that positive couple interaction is associated with improved health outcome for children (Heaton, Forste, 2008). A study on changes in men 's knowledge and attitude following health education on their role in preventing maternal deaths in a Nigerian community among 122 randomly selected men in a joint educational session on Safe Motherhood with a follow -up interview after three months showed that men were more likely to recognize a danger sign of pregnancy and delivery (Omokhoa, 2016). According to Sen et al (2007), men as partners and decision makers within families and communities need to be addressed so that they become caring and supportive to women's health care. Studies have also shown that interventions with men, designed with women`s participation and implementation with their consent have resulted in positive maternal health outcomes (Davis 2012).

\section{Statement of problem}

In Nigeria, where culture has been shown to be an important factor influencing relation to women's access to available reproductive health facilities, there is paucity of data on men's views with regard to maternal health (Yahaya, 2002). Men remain an authority in all the aspects of reproductive health from policy making to its implementation at grass root level. Health challenges and consequences such as maternal mortality and disabilities are high between the third trimester and first week after birth due to haemorrhage, sepsis and obstructed or prolonged labour assisted with infant morbidity and mortality due to non-involvement of men in antenatal care as decision makers (Martin, Mcnamara, Millot, Halleh and Hair, 2007). A longitudinal study conducted in the United States in 2002 with a sample size of 5404 women and their partners explored the effect of father involvement during pregnancy on receipt of prenatal care and maternal smoking; the findings of the study indicated that women whose partners were involved in their pregnancy care were 1.5 times likely to attend prenatal care in the first trimester and smokers reduced smoking by $36 \%$ as opposed to those whose partners were not involved in their pregnancy care (Martin, Mcnamara, Millot, Halleh and Hair, 2007). Many studies have been carried out on the role of the husband in determining the family size and contraceptive use (Becker et al, 2001). Only a few studies extended to include Safe motherhood (Mullany, 2010). There is a need for further research on how male involvement significantly affects maternal health care. Thaddeus and Maine (1994) stated that men can prevent maternal mortality by being able to recognize an obstetric emergency, take a care seeking decision and transport a woman to an appropriate facility. Male involvement allows better understanding of maternity issues and cares and ways of recognizing obstetrical emergency. Finding solution to common health problems early and improved better health for the entire family can be achieved through male involvement. Assessing male involvement in maternal health care and factors affecting it is vital towards improving and challenging male participation in maternal health care. This will enable care givers and policy makers to design strategies that will improve and maintain male participation. Generated findings from this study will propel strategies that will lead to increased male involvement in maternal health care. Improved male participation will 
enhance good joint decision making and improve healthy seeking behaviour regarding maternal care. This will lead to a decline in maternal mortality. Hence, this study was undertaken to describe men's knowledge and identify factors affecting male involvement in maternal health care among men in Jimeta Metropolis, Adamawa State, Nigeria.

\section{MATERIALS AND METHODS}

\section{Study design: This was a descriptive cross sectional survey}

Sample size determination: This was by using the formular by Singha (2002), which was calculated thus:

$$
\left.\left.n=z^{2} \times p \times q=\frac{1.96^{2} \times(0.32)}{d^{2}}\right) \frac{\left(0.05^{2}\right.}{0.68}\right)=336
$$

Where $z=1.96$ which is $z$ value for $95 \%$ confidence limits, $p$ is the target population estimated to have a particular characteristic. $\mathrm{P}$ is therefore the proportion of men involved in maternal health in a study in a Northern Nigerian Community according to lliyasu et al, (2010) which was $32 \% . q=1-p=0.68, d=0.05 \%$ which is the acceptable error of the estimator at $95 \%$ confidence interval. A sample size of 370 was gotten and used for the study.

Sampling technique: A multi-stage sampling technique was employed. Jimeta Metropolis is made up of 12 wards and the wards where divided into 4 clusters namely; Clusters A, B, C, D. This way, individuals within a particular cluster with similar characteristics could be sampled. Each of these clusters was made up of 3 wards namely; Cluster A: Limawaa, Alkalawa, Nassarawo, Cluster B: Doubeli , Luggere, Gwadabawa, Cluster C: Jambutu, kofare, Yelwa and Cluster D: Karewa, Dougirei, Masakare From each of the above clusters, one ward was selected at random using paper basket method. Nassarawo, Doubeli, Jambutu and Karewa were randomly selected to represent clusters A, B, C and D respectively which were used for the study. Using systematic sampling method, respondents were selected from houses that had already been numbered within the communities based on availability of respondents at the time of the study. Questionnaires were proportionately distributed to respondents within the communities.

Inclusion criteria involved all men above 18 years of age who were married, had children in the last two years and consented to participate in the study.

Exclusion criteria involved all those who were not married and below the age of 18 years.

Instrument for Data: This was by the use of semi structured questionnaire which answered questions on knowledge of maternal health services, male involvement and factors affecting male involvement in maternal care. It had both opened and closed ended questions. The questionnaire was adopted from a study by Nantamu (2011) which was validated and adjusted to suite the environment where the study is carried out and found suitable for the study. The questionnaire identified the availability and quality of health services in the study area, knowledge on maternal health services, male involvement in maternal health care, factors affecting involvement in maternal health care and reasons for not participating in maternal health care were elicited. The questionnaires were self-administered to respondents with the aid of research assistants. Informed consent was obtained from each participant ensuring them of confidentiality. The perception of respondents was assessed by putting the questions on a Likert's scale. The questions on Likert's scale had questions that ranged from very good, good, undecided, fair and poor. On the Likert scale, respondents were required to choose one appropriate response from the statements. The responses were scored. Respondents who scored below the mean were regarded as having poor knowledge and poor involvement in maternal health services while those with scores up to or above the mean were regarded as having good knowledge and involvement in maternal health care.

Data analysis and Presentation: The questionnaires were checked for completeness, data was cleaned, coded and analyzed using the Statistical Package for Social Sciences Version 21. Results were presented in Tables and Charts. Chi square was used to test for statistical significant difference between categorical variables and the level of significance was set at 0.05 .

\section{RESULT}

A total of 370 questionnaires were distributed and 343 were retrieved giving a response rate of $92.7 \%$. Table 1 shows that, $40.4 \%$ of respondents were within the ages of $28-37$ years old, $36.7 \%$ were civil servants, $33.8 \%$ had attended secondary education. Table 2 shows that, more than half of the respondents $(51.9 \%)$ were polygamous, almost all (80.2) the respondents reside with their spouse and decision making was mainly by the husbands (48.7\%). Table 3 shows that, majority (70.8\%) of the respondents did not know the number of times a woman 
should attend antenatal care. More than half $(65.1 \%)$ of the respondents did not know the services offered to women at antenatal clinic, women and children during puerperium (65.5\%) and $58.9 \%$ did not know the danger signs of pregnancy. Majority (59.5\%) of the respondents were aware that women need the services of a skilled birth attendant at delivery and $54.2 \%$ knew the services offered to women during delivery. Almost half (48\%) of the respondents had $4-5$ children. For $53 \%$ of respondents, average waiting time for respondents in the hospital was 30 minutes to 1 hour. More than half (52\%) of the respondents accompany their wives for delivery (chart 1). Less than half of the respondents provide funds for antenatal care $(38.3 \%)$ and postnatal services $(26 \%)$ while $52.1 \%$ provided funds for delivery services. Some respondents $(56.8 \%, 76.5 \%$ and $43.4 \%)$ gave consent to their wives to attend antenatal, delivery and post-natal visits respectively (chart 2). Table 4 shows that, the attitude of health workers towards men was poor $(69.1 \%)$ as majority of the men were not allowed in clinics and labour rooms $(88.6 \%)$. Table 5 shows that the major factors affecting non-involvement in maternal health care were; religious/cultural factor (31.3\%), ignorance $(20 \%)$ and financial constraints $(17.4 \%)$.

The result on relationship between socio demographic characteristics and male involvement in maternal health care showed no significant difference between the ages and religion of respondents with male involvement in maternal health care $\left(X^{2}=2.1, d f=1, P\right.$ value $=0.1515$ and $X^{2}=1.680, d f=1, P$ value $=0.1949$ respectively). $A$ significant difference was observed between educational attainment and ethnicity with male involvement in maternal health care $\left(x 2=26.43\right.$, $p$ value $<0.0001$ and ethnicity $X^{2}=47.24$, $p$ value $<0.0001$ respectively) (Table 6 ). Men's knowledge and involvement in maternal health care was not statistically significant, $x^{2}=0.2710, p$-value $=0.6026$ (Table 7). Health workers attitude towards male involvement in maternal health care was not statistically significant with $x^{2}=1,477, p$-value $=0.224$ (Table 8). There was an association between couples joint decision making and male involvement in maternal health care, $x^{2}=63.3, p$ value $=0.0001$ (Table 9).

\section{DISCUSSION}

The socio-demographic patterns showed that majority of the respondents $(40.5 \%)$ were aged 28 to 37 , which is typical of a community with high fertility. The educational status of respondents was of average as $56.6 \%$ of the respondents had attained secondary education. A huge number of the respondents were Muslims (51.0\%) and Fulani dominated $(32.06 \%)$, although there were a number of other tribes which include; Lakka, Bachama, Kilba, Michika, Mbula and Bura in the study area. More than half of the respondents had a polygamous marriage relationship (51.9\%) which is no doubt owing to the predominance of Islam in the study area which allows for polygamy. Only $36.23 \%$ of the respondents made joint decisions with their spouses. This is similar to the findings from a study conducted in India by Awasthi et al (2008) which showed that, only $28.61 \%$ of respondents took a joint decision with their partners at delivery. This may be attributed to the patriarchal nature of the predominant Fulani culture although the level of literacy in Jimeta Metropolis is fair. Majority of the respondents lived close to a health facility $(83.7 \%)$ with less than one hour tracking away from the health facility. Majority of the respondents $(52.5 \%)$ said they had to wait 30 minutes to one hour in the hospital before their wives were attended to. This is most likely as a result of staff shortage in the hospital. Long waiting time at the facility has been shown to be a deterrent for male involvement in maternal health services (Mullick, 2005).

Most respondents (53.9\%) were aware that pregnant women need to be attended to by a skilled birth attendant at a health facility. This is similar to a study conducted in South West of Nigeria, where $98.9 \%$ of the respondents were aware of the need for institutionalized maternal health care (Adenike et al, 2013). Similarly, findings from another South Western study in Nigeria showed men's high level of awareness on maternity care (Odimegwu et al, 2005). Despite the fact that majority of the respondents are aware that women need to be delivered with the assistance of a skilled birth attendant, there have been further reports of low utilisation of skilled birth attendants in Northern Nigeria. This posed a challenge for the progress in achieving MDG 5 in the region (Ezeanochie, Olagbuji, Agholor and Okonofua (2010). A population-based random survey of 6,809 women in Northern Nigeria showed a high rate of utilisation of unskilled birth attendants (Doctor and Dahiru, 2010). The data showed that unskilled birth attendants were more likely to deliver low quality maternity care when compared to skilled health workers. This is in line with the findings from the 2008 NDHS, which suggested that if the trend continues attaining the MDG 5 in Northern Nigeria would be a nightmare (Ezeanochie, Olagbuji, Agholor and Okonofua (2010). Another report by Dalyop et al (2010) also demonstrates similar results of high use of unskilled birth attendants in North Central Nigeria, and its negative effects on maternal health. Poor referral practices by traditional birth attendants in North-central Nigeria, and its negative consequences for maternal health indicators has also been reported (Abodunrin, Akande, Musa, Aderibigbe, 2010).

The low knowledge of men on the number of times a woman should attend antenatal care (ANC), the kind of services rendered to the women during antenatal visits and inability to recognize danger signs in pregnancy is similar to an Indian study where only $23.6 \%$ of men were aware of complications in pregnancy (Awasthi et al, 2008). This findings is also similar to that in South Africa by Kasolo and Ampaire (2000), where the overall knowledge of males was 33.3\% but contrary to a study in El Salvador by Carter (2005) where overall knowledge was high (90\%). This finding is better than that of a Kenyan study by Nanjala and Wamalwa (2012), where majority of the respondents had poor knowledge of maternal health care. The overall level of male knowledge in maternal health care was low. 
Less than half of the respondents (46.9\%) accompany their wives for delivery, while $(27.2 \%)$ and $(8.7 \%)$ accompany their wives to antenatal and post-natal clinics respectively. These findings corroborate with that of another study in Northern Nigeria where only $13 \%, 18.7 \%$ and $12 \%$ of men accompanied their wives for antenatal, delivery and postnatal care respectively (lliyasu et al, 2010). Study by Olugbenga-Bello, Asekun-Olarinmoye, Adewole, Adeomi and Olarewaju (2013) in Atelewo community in Osogbo, Osun State, Nigeria showed that only 2 out of 10 respondents follow their wives for antenatal care visits and also to the labour ward. This is in keeping with other studies (Mullick et al., 2005). Men's presence and their participation at the health facilities during antenatal care visit of their wives will help boost the morale of their wives and also bring about a greater sense of commitment of both parents to having healthy mothers and babies as evident from other studies (Mullick et al., 2005; Mullay et al., 2005; Stycos, 1996).

About attitude towards antenatal care, nearly half of the respondents agreed that men should accompany their wives for antenatal care visit. A similar finding about the role of partners during maternity in a study involving men in maternity revealed that respondents felt that there is need for males to accompany their wives to the hospital during delivery (Barua (2005). In a study on male involvement in maternity health care in Malawi, participants described male involvement to be a strategy for fast services for women while those without partners received unfair services, in addition it was seen as a foreign concept and an act of love (Kululanga, Sundby and Ellen, 2012). According to Pulerwitz, Deirdre, Akinrinola and Susheela in Millenium Project, approaches involving men in sexual and reproductive health care help support women's health like teach husbands about danger signs of labour, how to develop transport plan, the benefit of family planning to women's health, serve as agents for positive change where programmes are structured and services delivered wherever they are, working with men as sexual partners, fathers and community leaders.

The commonest reason stated by men for not participating in maternal health care include; religious/cultural factor, health system factor, attitude of health workers, long waiting time, financial constraint and ignorance of the need for them to participate. There is therefore the need for more enlightenment of men about the need for involvement in maternal health care.

The association between educational level and male involvement in maternal health care was statistically significant with $p<0.0001$. This implies that men who had formal education are more likely to be involved in their wives' health care than those who have not attended any formal education. Men who made decisions jointly with their spouses were more likely to participate in maternal health care than their counterparts who did not $(p<$ $0.0001)$.

\section{CONCLUSION}

Majority of the respondents were aware that pregnant women need to be attended to by a skilled birth attendant at a health facility but had little knowledge on the services provided. The level of male involvement in maternal health care was low. Factors associated with low male involvement in the study were socio-cultural and health system factors. There is need for the males to be more educated on the need to be involved in maternal health care and couple's joint decision making. This will improve maternal health and reduce mortality among women. 


\section{Tables}

Table 1: Socio-demographic Characteristics of Respondents

\begin{tabular}{|c|c|c|}
\hline Characteristic & Frequency & Percentage (\%) \\
\hline \multicolumn{3}{|l|}{ Age } \\
\hline $18-27$ & 92 & 27.0 \\
\hline $28-37$ & 139 & 40.4 \\
\hline $38-49$ & 112. & 32.6 \\
\hline Total & 343 & 100 \\
\hline \multicolumn{3}{|l|}{ Occupation } \\
\hline Civil servant & 126 & 36.7 \\
\hline Artisan & 57 & 16.6 \\
\hline Petty trader & 68 & 19.8 \\
\hline Farmer & 42 & 12.2 \\
\hline Others & 50 & 14.5 \\
\hline Total & 343 & 100 \\
\hline \multicolumn{3}{|l|}{ Education status } \\
\hline Primary & 78 & 27.7 \\
\hline Secondary & 116 & 33.8 \\
\hline Tertiary & 94 & 22.8 \\
\hline Not formally educated & 55 & 16.0 \\
\hline Total & 343 & 100 \\
\hline \multicolumn{3}{|l|}{ Religion } \\
\hline Islam & 175 & 51.0 \\
\hline Christianity & 168 & 49.0 \\
\hline Total & 343 & 100 \\
\hline \multicolumn{3}{|l|}{ Ethnicity } \\
\hline Fulani & 110 & 32.0 \\
\hline Hausa & 62 & 18.1 \\
\hline Yoruba & 27 & 7.9 \\
\hline Ibo & 38 & 11.1 \\
\hline Others & 106 & 30.9 \\
\hline Total & 343 & 100 \\
\hline
\end{tabular}

Table 2: Family Relationship of Respondents

\begin{tabular}{lll}
\hline Characteristics & Frequency & Percentage (\%) \\
Marriage relationship & & \\
Monogamous & 165 & 48.1 \\
Polygamous & 178 & 51.9 \\
Total & 343 & 100 \\
Resident with spouse & & \\
Yes & 275 & 80.2 \\
No & 68 & 19.8 \\
Total & 343 & 100 \\
Decision making & & \\
Husband & 167 & 48.7 \\
Wife & 48 & 14.0 \\
Both & 128 & 37.3 \\
Total & 343 & 100 \\
\hline
\end{tabular}


Table 3: Knowledge of respondents on maternal health care

\begin{tabular}{lll}
\hline Variables & Frequency & Percentage (\%) \\
Aware of number of times a woman should attend ANC & & 29.2 \\
Yes & 100 & 70.8 \\
No & 243 & 100 \\
Total & 343 & 34.9 \\
Knows the services offered to women in ANC & & 65.1 \\
Yes & 120 & 100 \\
No & 223 & 41.1 \\
Total & 343 & 58.9 \\
Knows the danger signs of pregnancy & & 100 \\
Yes & 141 & \\
No & 202 & 59.5 \\
Total & 343 & 40.5 \\
Aware women need a Skilled Birth Attendant & & 100 \\
Yes & 204 & \\
No & 139 & 54.2 \\
Total & 343 & 45.7 \\
Knows the services offered to women during delivery & & 100 \\
No & 186 & \\
Total & 157 & \\
Knows the services offered to mothers and children & & \\
during puerperium & 343 & 34.4 \\
Yes & & 100 \\
No & 118 & \\
Total & 225 & 343 \\
\hline
\end{tabular}

Table 4: Respondents' perception of health services

\begin{tabular}{lll}
\hline Characteristics & Frequency & Percentage (\%) \\
Quality of health services & & 18.6 \\
very good & 64 & 29.2 \\
Good & 100 & 39.4 \\
Fair & 135 & 12.8 \\
Poor & 44 & 100 \\
Total & 343 & 30.9 \\
Attitude of health workers towards men & & 69.1 \\
Good & 106 & 100 \\
Poor & 237 & 11.4 \\
Total & 343 & 88.6 \\
Are men allowed in clinics and labour rooms & & 100 \\
Yes & 39 & \\
No & 304 & 343 \\
Total
\end{tabular}

Table 5: Factors affecting male involvement in maternal health care

\begin{tabular}{lll}
\hline Variable & Frequency & Percentage \\
lgnorance & 89 & 25.9 \\
Religious/cultural factor & 97 & 28.2 \\
Financial constraints & 65 & 18.9 \\
Long waiting time in health & 53 & 15.4 \\
facilities & & \\
Poor attitude of health workers & 39 & 11.4 \\
Total & 343 & 100 \\
\hline
\end{tabular}




\section{Charts:}

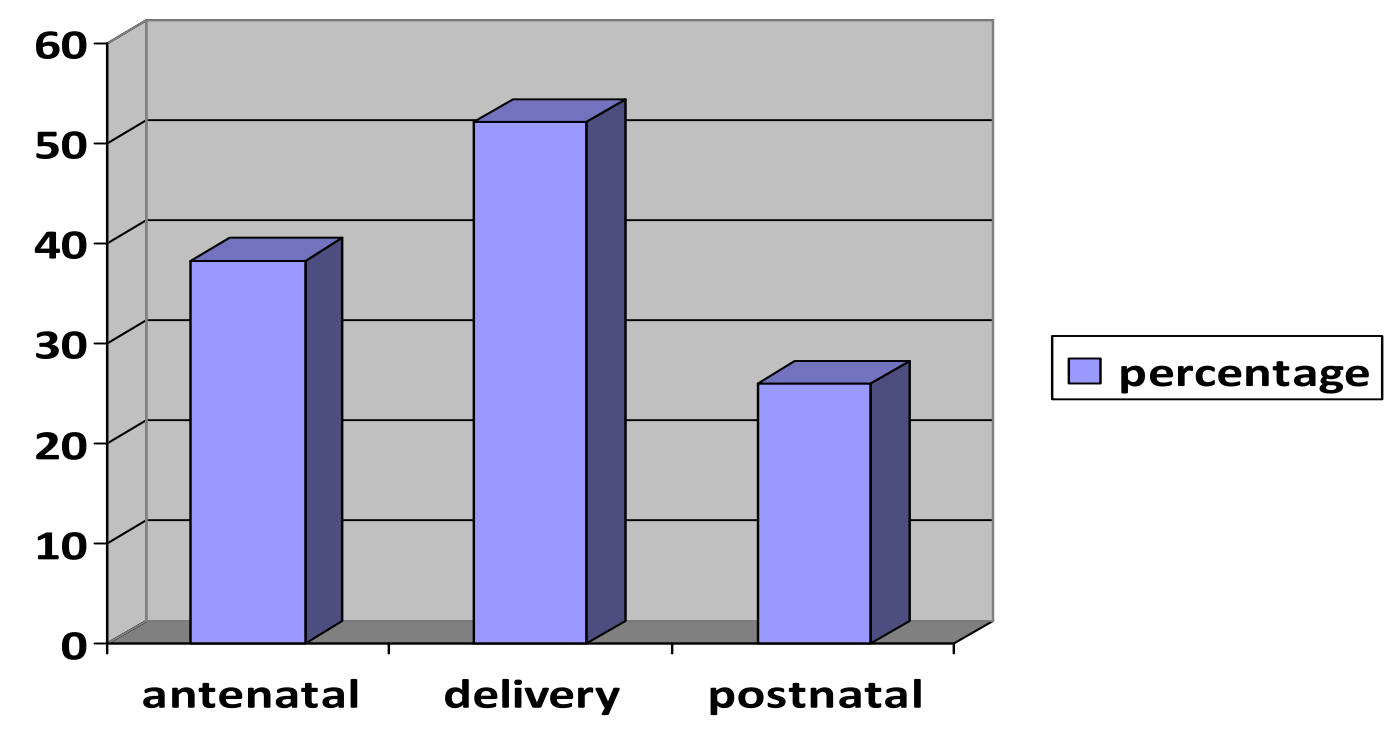

Chart 1: Percentage of men who accompany their wives to seek maternal health

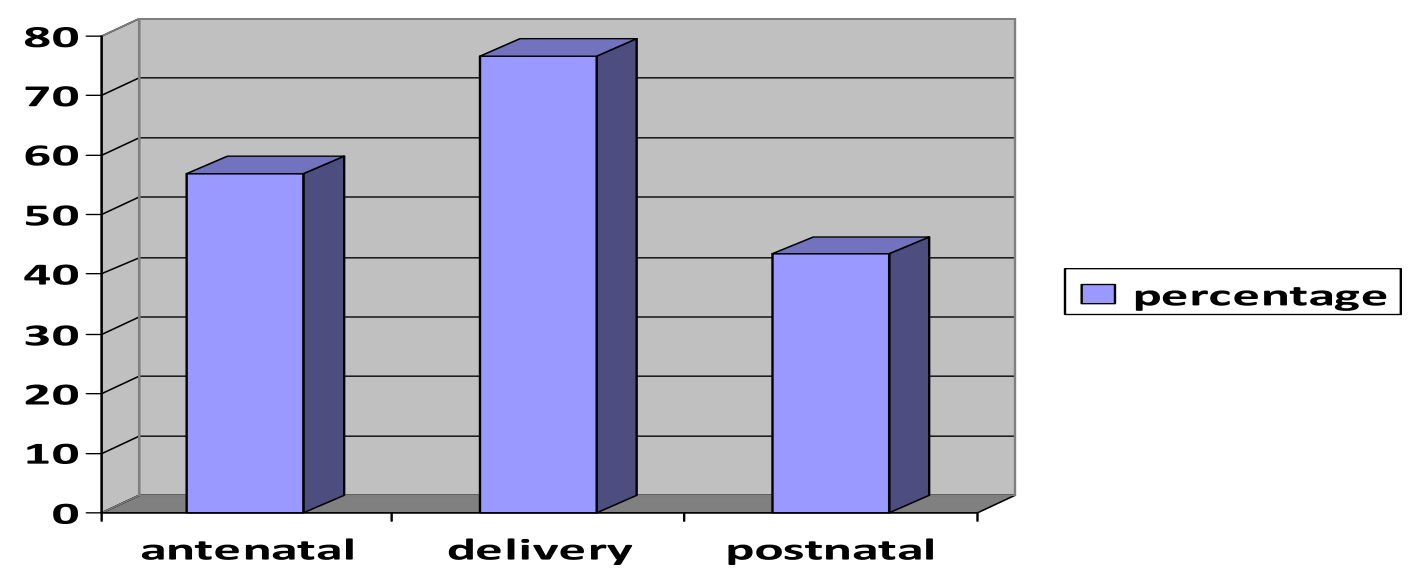

Chart 5: Percentage of men who give consent to their wives to attain maternal health care services 
Table 6: Association between socio demographic characteristics and male involvement in maternal health care $(n=343)$

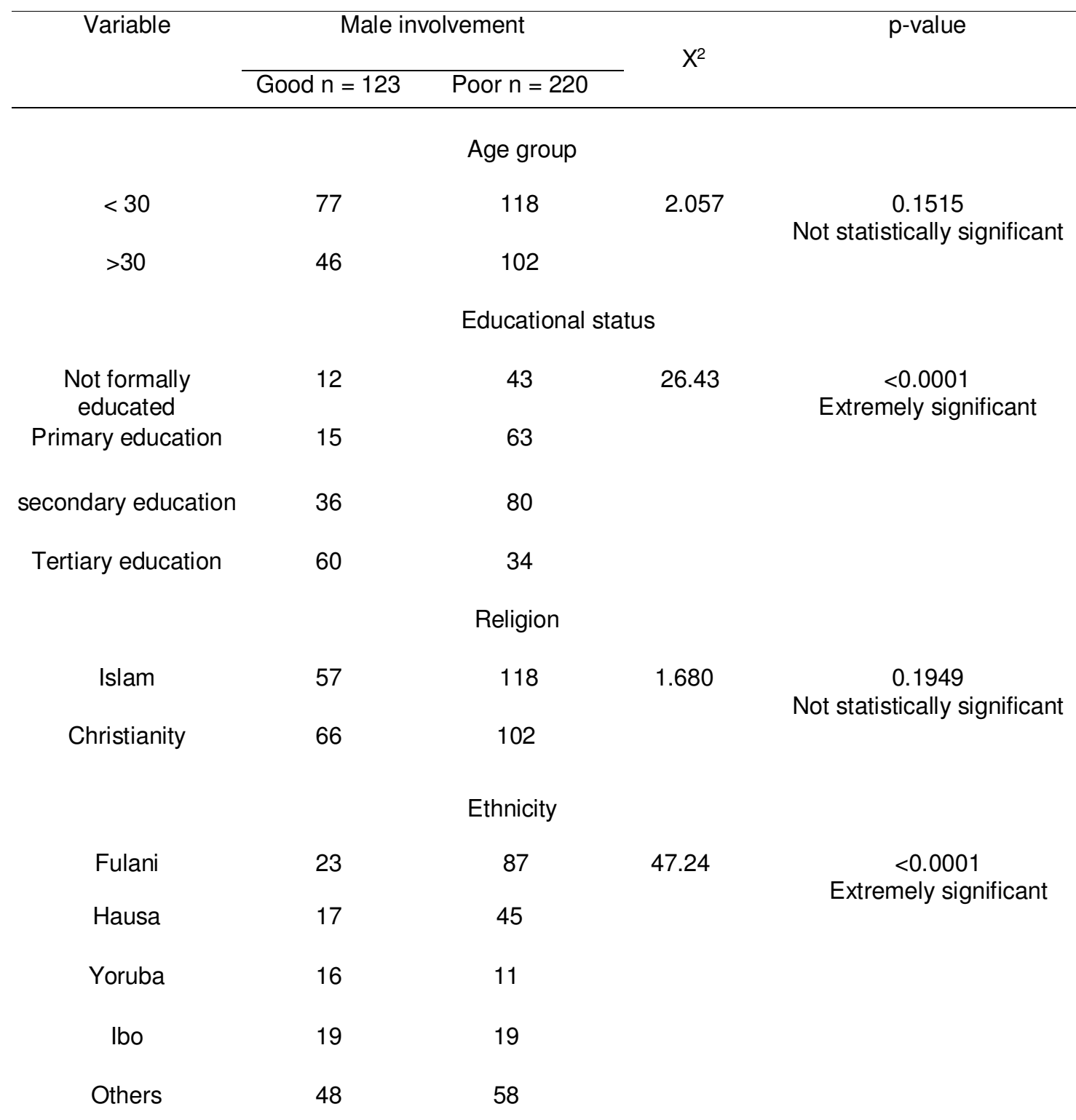

Table 7: Knowledge of Maternal health Care and Male involvement in Maternal health Care

\begin{tabular}{|c|c|c|c|c|}
\hline Variable & \multicolumn{2}{|c|}{ Male Involvement } & $\mathrm{X} 2$ & $P$ value \\
\hline $\begin{array}{l}\text { Knowledge of } \\
\text { Maternal Health Care } \\
\text { Health care }\end{array}$ & Good & Poor & & \\
\hline Good & 74 & 126 & 0.2710 & 0.6026 \\
\hline Poor & 49 & 94 & & Not statistically significant \\
\hline
\end{tabular}


Table 8: Attitude of Health workers and Male involvement in Maternal health Care

\begin{tabular}{|c|c|c|c|c|}
\hline Variable & \multicolumn{2}{|c|}{ Male Involvement } & $\mathrm{X} 2$ & $P$ value \\
\hline $\begin{array}{l}\text { Attitude of Health } \\
\text { Workers towards }\end{array}$ & Good & Poor & & \\
\hline Good & 43 & 63 & & \\
\hline Poor & 80 & 157 & 1.477 & $\begin{array}{l}0.224 \\
\text { Not statistically significant }\end{array}$ \\
\hline
\end{tabular}

Table 9: Joint Decision making and Male involvement in Maternal health Care

\begin{tabular}{lcccc} 
Variable & \multicolumn{2}{c}{ Male Involvement } & X2 & P value \\
Joint Decision making & Poor & & \\
& & & & \\
Good & 78 & 45 & & \\
Poor & 45 & 175 & 63.3 & $\begin{array}{c}<0.001 \\
\text { Extremely Statistically Significant }\end{array}$ \\
\hline
\end{tabular}

\section{REFERENCES}

Abodunrin OL, Akande TM, Musa IO, Aderibigbe SA (2010). Determinants of referral practices of clients by traditional birth attendants in Ilorin, north central Nigeria. Afr. J. Rep. Health, 2010, 14: p. http://www.ajrh.info. [accessed September 23, 2016]

Adenike IO, Asekun EO, Adewole O, Adeomi AA and Olarewaju SO (2013). Perception, attitude and involvement of men in maternal health care in a Nigerian community. J. of public health and epid 5(6): 262-270 available online at http://ww.academicjournals.org/JPHE. http://www.academicjournals.org. [accessed March 12, 2014]

Awasthi S, Nandan D, Mehrotra AK and Shankar R (2008). Male participation in maternal care in urban slums of district Agra. Indian J. of preventive Social medicine; 39(3\&4). http://www.sci-rep.com. [accessed June 4, 2015]

Barua A (2005) Husbands involvement in maternal care: young couples in Mahashtra. International centre for research and women

Becker S, Costenbader E (2001). Husbands and wives report of contraceptive use. Studies in family planning 32(2), 130-146. https://www.guttmacher.org/ [accessed March 15, 2014]

Bustamante-Forest R, Giarratano G (2004). Changing men's involvement in reproductive health and family planning. Nurs Clin North Am., 39 (2): 301-318. 10.1016/j.cnur.2004.02.001.View ArticlePubMedGoogle Scholar. https://reproductive-health-journal.biomedcentral.com. [accessed May 5, 2013

Davis J, Luchters S, Holmes W (2012). Men and maternal and newborn health: benefits, harms, challenges and potential strategies for engaging men. Compass: Women's and Children's Health Knowledge Hub. Melbourne, Australia. www.wchknowledgehub.com. [accessed March 1, 2015]

Doctor HV, Dahiru T (2010). Utilization of non-skilled birth attendants in northern Nigeria: A rough terrain to the health-related MDGs. African. J. Rep Health, p. 14. www.ncbi.nlm.nih.gov/pubmed. 2012 [accessed January 6, 2015]

Ezeanochie MC, Olagbuji BN, Agholor KN, Okonofua FE(2010). Attaining MDG 5 in northern Nigeria: Need to focus on skilled birth attendance, African J. of Reproductive Health, June 2010; 14[2]: 9-11. [Accessed 7/10/2016], ISSN -- e:2141-3606,1118-4841. African J of Reproductive Health, June 2010; 14[2]: 9-11. www.mamaye.org.ng Accessed 7/10/2016.

Heaton TB, Forste R (2008). Domestic Violence, Couple Interaction and Children's Health in Latin America. Journal of Family Violence, 23 (3): 183-193. 10.1007/s10896-007-9142-7.View ArticleGoogle Scholar. link.springer.com/article [accessed April 6, 2013]

Hogan MC, Foreman K J, Naghavi M(2010). Maternal mortality for 181 countries, 1980-2008: a systematic analysis of progress towards Millennium Development Goal 5," The Lance, 375( 9726), 1609-1623, 2010. View at Publisher - View at Google Scholar - View at Scopus. https://www.ncbi.nlm.nih.gov/pubmed. [accessed June 3, 2014]. 
International Conference on population and development (ICPD) (1994). Cairo, Eygpt. URL: http://www.un.org/popin/icpd2.htm . www.un.org/popin/icpd2.htm [accessed Mya 5, 2014].

lliyasu Z, Abubakar IS, Galadanci HS and Aliyu MH (2010). Birth preparedness, Complication readiness and fathers' participation in Maternity care in a Northern Nigerian Community. African J of Rep health 2010; 14(1): 21-32. www.bioline.org.br/ [accessed August 3, 2012].

Kululanga LI, Sundby J, Malata A, Chirwa E (2012). African J of Reproductive Health, 16(1):146. http://www.bioline.org.br/pdf?rh12016. www.bioline.org.br/pdf?rh12016 [accessed May 7, 2016]

Lucas AO, Gilles HM (2003). Family health. Short textbook of public health medicine for the tropics, 4th Edition, Arnold publishers pp. 319-335. www.abebooks.com. [accessed June 6, 2014].

Marion W, Carter1 and Ilene Speizer (2005). Salvadoran fathers' attendance at prenatal care, delivery, and postpartum care. Rev Panam Salud Publica/Pan American J. of Public Health, 18(3), 149 [accessed March 1, 2014].

Martin MT, Mcnamara MJ, Millot AS, Halleh T and Hair EC (2007). The Effect of Father Involvement during Pregnancy and Receipt of Prenatal Care and Maternal Smoking", Maternal and Child Journal 11: 595602. www.iiste.org/Journals [accessed March 7, 2014].

Millennium Development Goals (MDGs) Fact sheet No290 Updated May 2015 [accessed September 16, 2016]

Mullany BC, Becker S, Hindin M. J. (2007). The impact of including husbands in antenatal health education services on maternal health practices in urban Nepal: results from a randomized controlled trial. Health education and research, 22(2): 166-76. www.ncbi.nlm.nih.gov/pubmed [accessed October 15, 2015].

Mullick S, Busi, K and Wanjiru M (2005). Involving men in maternity care; Health service delivery issues: available at www.who.int accessed 20 October 2008. https://www.k4health.org/sites [accessed August 11, 2014].

Nanjala M and Wamalwa D (2011). Determinants of male partner involvement in promoting deliveries by skilled attendants in Busia, Kenya. Global J of Health sciences 4 (2), [accessed March 23, 2014]

Nantamu DP (2011). Factors associated with male involvement in maternal health care services in Jinja district, Uganda. Unpublished thesis at Makerere University School of Public Health. www.ncbi.nlm.nih.gov [accesed July 2, 2016].

Nigeria Demographic and Health Survey (2013). National Population Commission (NPC) [Nigeria] and ICF International. Abuja, Nigeria and Rockville, Maryland, USA: NPC and ICF International. https://dhsprogram.com/pubs [accessed March 28, 2014].

Nigeria Federal Ministry of Health (2011). Concept Note on Health System Strengthening Initiative, [accessed September 16, 2016].

Nigeria Millennium Development Goals 2013 Report. www.sparc-nigeria.com, [accessed September 23, 2016]

Nigeria Millenium Development Goal End Report (2015), Abridged version. www.mdgs.gov.ng. [accessed October 12, 2016].

Odimegwu C, adewuyi A, Odebiyi T, Aina B , Adesina Y, Olatubara O and Eniola F (2005). Men's Role in Emergency Obstetric Care in Osun State of Nigeria. Afr. J. Reprod. Health 9(3):59-71. www.ncbi.nlm.nih.gov/ 2013.

Omokhoa AA, Chukwunwendu AO (2016). Changes in men`s knowledge and attitudefollowing health Education on their role in Preventing Maternal deaths: An Exploratory Survey in a Nigerian Community. Sociaal Medicine, Vol 10, No 2.[accessed October 4, 2016].

Pulerwitz J, Wulf DA, Singh S. Involving men in reproductive Health. Contributions to development, Millenium Project. Background Paper to the Report. Public Choices, Private decisions, Sexual and Reproductive Health and the Millenium Development Goals. www.unmillenniumproject.org/documents/ [accessed October 7, 2016].

Sen, Gita, PiroskaÖstlin, Asha G (2007). Unequal, Unfair, Ineffective and Inefficient Gender Inequity in Health: Why it exists and how we can change it. Final Report to the WHO Commission on Social Determinants of Health. Women and Gender Equity Knowledge Network. www.who.int/social_determinants. .[accessed September 5, 2015].

Singha P (2002). An introductory text in biostatics. $3^{\text {rd }}$ edition 1145 . Gadza, Nigerian Limited. Kaduna Nigeria.

Stycos JM (1996). Men, Couples and Family Planning: a Retrospective Look. Working paper No. 96-12. Cornell University Population and Development Program, Ithaca, NY. www.academicjournals.org, [accessed September 6, 2014].

Sustainable Development Goals. Before the Sustainable Development Goals how did Nigeria really do with the Millenium Development Goals? http://nigeriahealthwatch.com.[accessed October 14, 2016]

Thaddeus S and Maine D (1994). Too far to walk; Maternal mortality in context, Soc Sci and Med, 38:1091-1110. www.ncbi.nlm.nih.gov.[accessed October 44, 2016].

Varkey LC, Mishra A, Das A, Ottolenghi E, Huntington D, Adamchak S, Khan ME, Homan F (2004).: Involving Men in Maternity Care in India. Frontiers in Reproductive Health Programme, Population Council, New DelhiGoogle Scholar, eldis.org/vfile/upload .[accessed September 4, 2014]

Were N (2009). Rural finance should target women. The New Vision newspaper, Tuesday December 2009 Pg 13. www.afdb.org.[accessed May 12, 2014]. 
White V, Greene M and Murphy E (2003) Men and reproductive health programs influencing gender norms. The synergy project. US Agency for International Development. URL: http://pdf.usaid.gov/pdf_docs/PNACU969.pdf. pdf.usaid.gov. [accessed July 4, 2014].

World Health Organization (2006), Women's Health in the WHO Africa Region: A call for action. Report of Regional Director. Fifth-eight session Yaounde, Cameroon 1-5 September 2008. http://apps.who.int .[accessed May 6, 2014].

World Health Organization. Causes of Maternal and Child deaths. Taking Stock of Maternal, Newborn and Child Survival 2000-1012 Decade Report. Preliminary data of a WHO systematic review of causes of maternal deaths, http://www.who.int/pmnch/topics/child/countdownreportpages 11-21.pdf.[accessed August 7, 2015].

World Health Organization (2012). Every woman, every child: From commitment to actions: the first report of the Independent Expert Review Group on information and accountability of women`s and children`s health. Geneva. www.who.int/woman_child_accountability [accessed September 8, 2016].

WHO, UNICEF, UNFPA, The World Bank (2012). Trends in maternal mortality: 1990 to 2010. Geneva: World Health Organization. whqlibdoc.who.int/publications .[accessed August 9, 2016].

World Health Organization (2013). Maternal and Newborn Health. Available at http://www.womendeliver.org/knowledge-center/facts-figures/maternal-health/. World Health Organization (2013). Maternal and Newborn Health. Available at http://www.womendeliver.org/knowledge-center/factsfigures/maternal-health .[accessed August 5, 2016].

World Bank (2014). Maternal Health. Available at http://www.womendeliver.org/knowledge-center/factsfigures/maternal-health .[accessed October 14, 2015].

World Health Organization (2014). Global Causes of maternal death: a WHO systemic analysis. The Lancet Global Health. 2(6): 323, doi:1016, Open acess:[accessed October 4, 2016].

World Health Organization (2015). Trends in maternal mortality: 1990 to 2015. Estimates by WHO, UNICEF, UNFPA, World Bank Group and the United Nations Population Division. http://apps.who.int/iris/bitstream .[accessed September 9, 2016].

Yahaya MK (2002). Analysis of women's reproductive health situation in Bida Emirate of Niger State, Nigeria. African. J. Rep Health 6(1):5064. www.ncbi.nlm.nih.gov/pubmed. .[accessed October 12, 2016].

Cite this Article: Mfuh AY, Lukong CS, Olokoba OE, Zubema HJ (2016). Male Involvement in Maternal Health Care in Jimeta Metropolis, Adamawa State, Nigeria. Greener Journal of Epidemiology and Public Health, 4(2): 027-039, http://doi.org/10.15580/GJEPH.2016.2.082216132 